\title{
Effects of the subject's awareness of the nature of the experiment upon conformity behavior
}

\author{
PEGGY JO WAGNER and MARVIN E. SHAW \\ University of Florida, Gainesville, Fla. 32601
}

A 2 by 2 by 2 factorial design was used to study the effects of instructions, type of stimuli, and stimulus order upon conformity behavior. Ss were given either standard instructions or instructions which warned them that the responses of others might not be valid; they responded to either Asch lines or geometric figures, and either the lines or the figures were presented first. Results revealed no differences in conformity between instructions, probably because all Ss perceived the situation as a study of conformity. Significant differences in conformity were observed as a function of type and order of stimuli. It was concluded that suspiciousness may reduce the level of conformity but not the pattern of conformity. It was suggested that one way to control for suspiciousness is to tell all Ss that they should be suspicious.

The problem of unwanted variables in research is an ancient one, but it continues to bedevil social-psychological research. Perhaps the most pervasive unwanted variable in psychological research is "suspiciousness of the experimenter's intent" or the S's awareness of what is being investigated. Today, it is almost universally accepted that the $S$ should be naive about the purposes of the $\mathrm{E}$, although, as McGuire (1969) has suggested, the results obtained by flagrant disregard of this "law" (e.g., Ebbinghaus's using himself as S) are replicated remarkably well by covert procedures. Nevertheless, most researchers seem to regard awareness of intent as an experimental artifact and believe that the possible effects of awareness of intent on experimental findings must be controlled for in some way.

McGuire (1969) has described some techniques that have been adopted in an attempt to control for S's awareness. The most common one is some form of deception whereby the $S$ is led to believe that the E's purposes are quite different from his actual purposes. The ethical questions surrounding the use of deceptive procedures have become especially prominent in recent years (e.g., see Baumrind, 1964; Kelman, 1967; Ring, 1967). At the opposite extreme is the use of informed Ss who are asked to behave "as if" they were true experimental Ss (Rosenberg \& Abelson, 1960; Kelman, 1967; Shaw \& Tremble, 1971). This kind of role-playing technique has proven to be reasonably effective, but there may still be some doubt about the validity of the findings. For example, after an extensive review of theoretical views and empirical data relevant to role playing as an alternative to deception, Miller concluded that "... the prospects for role-playing as an alternative to deception are very poor [1972, p. 634]." It seems clear that neither deception nor role playing provides a satisfactory solution to the problem of awareness of the E's intent. This report explores a possible alternative to these procedures.

Conformity behavior is a suitable area for testing alternative research techniques because there already exists a body of research showing that the degree of conformity is reduced when Ss are suspicious (Stricker, Messick, \& Jackson, 1967; Glinski, Glinski, \& Slatin, 1970) and that role playing does not yield results that are equivalent to those obtained by traditional techniques (Willis \& Willis, 1970). In these studies, however, there is some evidence that suspiciousness reduces the level of conformity but that the relationship between conformity and other variables is not changed. If so, the effects of suspiciousness could be controlled by informing all Ss about the general purpose of the experiment. Since the purpose of the experiment is usually to determine relationships rather than absolute degrees of conformity (or other behavior), the mere fact that awareness reduces the level of response does not alter the theoretical significance of results. The purpose of the present study was to determine whether the same pattern of results could be obtained when the $S$ is informed about the situation as when more traditional procedures are followed.

\section{METHOD \\ Subjects}

The Ss for this experiment were 40 male undergraduates enrolled in introductory psychology courses at the University of Florida. Participation in the study satisfied a portion of their course requirements.

\section{Apparatus and Materials}

The major piece of apparatus for this experiment was a Social Communication Laboratory, Model PR-18, manufactured by Research Media, Inc. This is similar to the Crutchfield-type conformity apparatus, but is more flexible in that it can be used to provide true information as well as bogus information to the Ss. The unit used in this study consisted of a master console and five $\mathrm{S}$ stations. This equipment was installed in six booths which were arranged in such a way that each one was approximately the same distance from a projection screen mounted in the front of the room. The master console was placed in one of the center booths. The same booth also contained a Carousel $2 \times 2$ in. projector which was used to project stimuli on the projection screen.

The stimuli consisted of a set of 13 Asch-type lines and a set of 13 geometric figures. When presented with the line stimuli, the S's task was to identify the line which was the same length as a standard line. When the geometric figures were presented, the task was to identify which of three figures had the largest area. Research has shown that conformity is generally less with the relatively unambiguous line stimuli than with the more 
Table 1

Mean Conformity as a Function of Instructions, Type of Stimuli, and Order of Stimulus Presentation

\begin{tabular}{lccccc}
\hline & \multicolumn{2}{c}{$\begin{array}{c}\text { Standard } \\
\text { Stimulus } \\
\text { Order }\end{array}$} & & \multicolumn{2}{c}{$\begin{array}{c}\text { "Honest" } \\
\text { Instructions }\end{array}$} \\
\cline { 2 - 3 } \cline { 6 - 7 } & Lines & Figures & & Lines & Figures \\
\hline Lines-Figures & 0.4 & 2.2 & & 0.1 & 1.7 \\
Figures-Lines & 0.8 & 3.7 & & 0.2 & 3.7 \\
\hline
\end{tabular}

ambiguous geometric figures. Each set of stimuli contained eight critical stimuli and five noncritical stimuli.

\section{Design}

The experimental design was a mixed 2 by 2 by 2 factorial, involving two kinds of instructions, two types of stimuli, and two orders of stimulus presentation. Half of the Ss were given standard conformity instructions, i.e., they were told that this was a study of perception, and no mention was made of the possibility that some of the responses they would see would not be the true responses of the other persons in the room. The other half of the Ss were told that sometimes the lights on their panel would reflect the responses of others and sometimes the E would determine what the responses would be. In short, these Ss were told that they should be suspicious of the validity of the information concerning other Ss' judgments.

All Ss responded to both the line and the geometric figures. In each instruction condition, half of the Ss responded to the line stimuli first, whereas the other half were presented the geometric figures first.

\section{Procedure}

The Ss were run in groups of five. When all Ss had been seated in the booths, the $\mathrm{E}$ read the appropriate instructions and answered any questions that were asked. After each $S$ was designated No. 5, the first stimulus slide was projected on the screen. Ss were asked to respond in order so that all Ss actually responded last. The $\mathrm{E}$ signaled the responses of Positions 1, 2, 3, and 4. On noncritical trials, the $E$. always signaled correct responses for the three bogus positions; since the correct choice was obvious, the judgments indicated to Ss corresponded to the actual judgments of other Ss.

On each of the critical trials with each set of stimuli, the E signaled incorrect responses for each of the first four positions and recorded the number of times each $S$ 's response agreed with the presumably unanimous majority. This number was taken as the measure of conformity.

\section{RESULTS}

The mean conformity score for each cell of the experimental design is presented in Table 1 , and a summary of the analysis of variance of these scores is presented in Table 2 . It can be seen from Table 2 that, although standard instructions produced greater conformity (mean $=1.78$ ) than did "honest" instructions (mean $=1.43$ ), there was no significant difference between the two types of instructions. There was a highly significant difference between types of stimuli; Ss conformed more to geometric figures than to the lines (means $=2.82$ and 0.38 , respectively; $\mathrm{p}<.001)$.

There was also a significant effect attributable to order $(p<.05)$ and to an interaction between stimuli and order $(p<.01)$. Greater conformity was observed when the geometric figures were presented first (means = 2.10 and 1.10 for figures-lines and lines-figures, respectively); however, the difference between stimuli was significantly greater when the geometric figures were presented first (means $=0.50$ for lines and 3.70 for figures) than when lines were presented first (means = 0.25 for lines and 1.95 for figures).

\section{DISCUSSION}

Unlike previous research, no significant differences in conformity were found between informed and uninformed Ss. This could have been due to the fact that all Ss revealed some degree of suspiciousness. When asked, "What did you think was the purpose of this experiment?" all Ss said they believed the purpose was to study conformity behavior. However, no $S$ in the uninformed group indicated that he believed the responses of the other Ss were bogus. Although we cannot rule out the possibility that the observed results were due to suspiciousness or awareness of the E's intent, this fact should be of secondary consideration. The important finding of this study is that differences in conformity between line and figure stimuli were highly significant. Furthermore, the differences were in the same direction and of the same general magnitude as expected from theoretical considerations and as observed in several earlier studies where suspicion was not a factor as in the present study (see-Shaw, 1971). This finding strongly suggests that awareness of the E's (general) intent may not be as great a source of contamination as commonly believed. It would seem that awareness of intent reduces the level of response but does not significantly change the pattern of response.

There is one new finding that is worthy of note: the magnitude of the effect of stimulus ambiguity upon conformity was significantly affected by the order in which the stimuli were presented to the Ss. This finding could be an artifact of the method of scoring. If one considers the total number of conformity responses to the lines, it is ubserved that $33 \%$ of these responses occurred when the lines were first and $67 \%$ when the figures were presented first. The percentages are almost identical for figures $(35 \%$ and $65 \%)$. In short, the relatively greater difference between lines and figures may be a consequence of the fact that there was more conformity to figures than to lines and greater conformity when figures were presented first than when lines were presented first. It is probable that initial exposure to the figures created uncertainty about the correctness of the S's judgment which increased conformity under all conditions. Whatever the reason, these findings reemphasize the need to control for order effects, preferably by using independent stimulus groups.

In summary, it is suggested that awareness of the general intent of the investigator does not alter the pattern of response

Table 2

Summary of Analysis of Variance of Conformity Scores

\begin{tabular}{lrrr}
\hline \multicolumn{1}{c}{ Source } & df & Mean Square & \multicolumn{1}{c}{ F } \\
\hline Between Ss & & & \\
$\quad$ Instructions (I) & 1 & 2.45 & 0.70 \\
Stimulus Order (O) & 1 & 20.00 & $5.68^{*}$ \\
I by O & 1 & 0.05 & 0.01 \\
$\quad$ Error & 36 & 3.52 & \\
Within Ss & & & \\
Stimuli (S) & 1 & 120.05 & $104.39 \dagger$ \\
I by S & 1 & 0.20 & 0.17 \\
O by S & 1 & 11.25 & $9.78^{* *}$ \\
I by O by S & 1 & 0.80 & 0.70 \\
Error & 36 & 1.15 & \\
\hline$\quad * p<.05$ & $* * p<.01$ & & $t p<.001$
\end{tabular}


to various conditions, although the magnitude of response may be reduced. If so, incorrect conclusions will be drawn only if one attempts to evaluate the absolute amount of conformity-which is probably impossible anyway. If the investigator wisely restricts his conclusions to relative differences among experimental conditions, his conclusions should be valid even though the $S$ is aware of his intent. If so, then the $E$ could insure that the level of awareness is similar for all Ss by simply informing them of the general nature of the situation in which they are placed.

\section{REFERENCES}

Baumrind, D. Some thoughts on ethics of research: After reading Milgram's "Behavioral study of obedience." American Psychologist, 1964, 19, 421-423.

Glinski, R. J., Glinski, B. C., \& Slatin, G. T. Nonnaivety contamination in conformity experiments: Sources, effects, and implications for control. Journal of Personality \& Social Psychology, 1970, 16, 478-485.

Kelman, H. C. Human use of human subjects: The problem of deception in social psychological experiments. Psychological Bulletin, 1967, 67, 1-11.

McGuire, W. J. Suspiciousness of experimenter's intent. In R.
Rosenthal and R. L. Rosnow (Eds.), Artifact in behavioral research. New York: Academic Press, 1969. Pp. 13-57.

Miller, A. G. Role playing: An alternative to deception? A review of the evidence. American Psychologist, 1972, 27, 623-636.

Ring, K. Experimental social psychology: Some sober questions about some frivolous values. Journal of Experimental Social Psychology, 1967, 3, 113-123.

Rosenberg, M. J., \& Abelson, R. P. An analysis of cognitive balancing. In M. J. Rosenberg et al (Ed.), Attitude organization and change. New Haven: $\mathrm{Y}$ ale University Press, organization and chan

Shaw, M. E. Group dynamics: The psychology of small group behavior. New York: McGraw-Hill, 1971.

Shaw, M. E., \& Tremble, T. R., Jr. Effects of attribution of responsibility for a negative event to a group member upon group process as a function of the structure of the event. group process as a function of

Stricker, L. J., Messick, S., \& Jackson, D. N. Suspicion of deception: Implications for conformity research. Journal of Personality \& Social Psychology, 1967, 5, 379-389.

Willis, R. H., \& Willis, Y. A. Rolt playing versus deception: An experimental comparison. Journal of Personality \& Social Psychology, 1970, 16, 472-477.

(Received for publication January 4, 1973.) 